\title{
Los temas políticos que ocuparon al editor Antonio José Valdés en EII Irís de Jalisco (1823-1825)
}

Ma. Eugenia Claps Arenas ${ }^{1}$ mariaeugenia.claps@unicach.mx
Political issues which occupied

the editor Antonio José Valdés in El Iris de Jalisco (1823-1825)

\section{Resumen}

Este trabajo analiza los temas políticos que ocuparon al editor cubano Antonio José Valdés en El Iris de Jalisco, periódico del que fue editor entre 1823 y 1825. Estos años fueron trascendentes en la historia mexicana, ya que marcan el fin de la monarquía constitucional encabezada por
Iturbide y el principio de la primera República federal, por lo que resulta de gran interés revisar las propuestas y la posición política de Valdés en esos momentos cruciales de la formación del Estado nacional, pues fue un personaje influyente en la edición de periódicos como el que aquí se analiza.

Palabras clave: Antonio José Valdés, El Iris de Jalisco, República, federación, Monarquía Constitucional.

\section{Abstract}

The following article focuses on the political issues analyses by Antonio Jose Valdes, the Cuban editor of El Iris de Jalisco, journal in which Mr. Valdes was editor between 1823 and 1825. These years were transcendental in Mexican history because they comprise the end of Iturbide's Constitutional Monarchy and the foundation of the first Federal Republic. Accordingly, the review of the proposals and the political posture of Mr. Valdes is of great interest in light of the pivotal moment in the formation of the Mexican National State and because Mr. Valdes was an influential character due to his journalistic activities in a state, Jalisco, that was highly relevant for the newly formed Mexican nation.

Key words: Antonio José Valdés, El Iris de Jalisco, Republic, Federation, Constitutional Monarchy.

1 Centro de Estudios Superiores de México y Centroamérica de la Universidad de Ciencias y Artes de Chiapas, México.

Bugambilia 30, Fraccionamiento La Buena Esperanza, C.P. 29243, San Cristóbal de Las Casas, Chiapas, México.

Letras Históricas / Número 19 / Otoño 2018-invierno 2019 / México / pp. 157-179 / ISSN: 2448-8372 


\section{Introducción ${ }^{2}$}

El Iris de Jalisco ${ }^{3}$ fue una publicación trisemanal editada en Guadalajara por el cubano Antonio José Valdés entre diciembre de 1823 y febrero de 1825, periodo importante para la historia mexicana, pues abarca tanto la elaboración del proyecto y acta constitucional posteriores al Imperio iturbidista como el principio de la primera República federal en el país, bajo la Constitución política promulgada en octubre de 1824.

El objetivo de este periódico era favorecer en sus páginas "la ilustración del pueblo mexicano," para lo que su editor se propuso, entre otras cosas, publicar las discusiones del Soberano Congreso Constituyente y las del Congreso de Jalisco, noticias locales, nacionales e internacionales, así como las órdenes de gobierno. Adicionalmente, Valdés redactaba artículos editoriales y comentarios sobre lo publicado, firmados con la frase "Hasta otra vez", lo que permite conocer de manera directa cuáles fueron sus opiniones. Además, en muchas ocasiones hacía llamadas a pie de página a lo largo de los diversos documentos que insertaba, donde exponía sus puntos de vista sobre el asunto en ellos tratado. Para más señas, El Iris fue un periódico producido en la imprenta del diputado jalisciense Urbano San Román.

Este editor cubano tuvo una participación pública destacada en México desde su llegada al país alrededor de 1821; fue diputado por Guadalajara en el Congreso Constituyente del Imperio en 1822, e integrante de la comisión de su Constitución (Andrews, 2012, pp. 55-71). ${ }^{4}$ En el momento que nos ocupa seguía siendo un personaje con influencia a raíz de la edición del periódico jalisciense, que aprovechó para exponer sus convicciones políticas y argumentarlas con el propósito de conseguir su implementación tanto en Jalisco como en el resto de la República, así como para desacreditar a aquellos a quienes consideraba sus adversarios.

Un borrador de este trabajo fue presentado en el Seminario Interinstitucional de Historia Política del Instituto Mora. Agradezco los comentarios y sugerencias que recibí, así como las lecturas proporcionadas por Israel Arroyo.

3 En adelante citado como El Iris en el texto. Este material fue obtenido y transcrito de la Hemeroteca Nacional Digital de México, consultada entre noviembre de 2015 y marzo de 2016.

4 En este artículo de Andrews se puede consultar una biografía sucinta del personaje. A ella puedo añadir que según el mismo Valdés apuntó en El Iris, quien lo empleó en la secretaría de Guadalajara cuando estuvo en la corte de Madrid en 1820 fue Antonio Porcel, ministro español de Gobernación de Ultramar (Fervet Sol), El Iris de Jalisco, 17 de mayo de 1824, núm. 74, p. 5. 
Más tarde, entre noviembre de 1825 y agosto de 1826, se encargó en la ciudad de México del importante y conocido periódico El Águila Mexicana, donde reprodujo el mismo esquema de defensa de sus ideas y ataque a sus opositores (Tella, 1994, 159). ${ }^{5}$

En este sentido, se debe también apuntar que Valdés ya tenía una amplia experiencia en la edición de periódicos en otras regiones de Hispanoamérica. Él mismo señala en El Iris lo siguiente: "He publicado diez periódicos: tres en La Habana, dos en Buenos Aires, dos en México y tres en Guadalajara". ${ }^{6}$ Y en efecto, en Buenos Aires, por ejemplo, fue redactor en 1815 de El Censor, órgano crítico de los actos del gobierno central, por lo que tuvo algunos problemas con la Junta Protectora de la Libertad de Imprenta (Goldman, 2000, pp. 9-20). ${ }^{7}$ Finalmente, salió de su redacción para asumir una responsabilidad diplomática en Europa, de la que ya no regresó al Río de la Plata (Goldman, 2000, p. 14). ${ }^{8}$

El objetivo del presente trabajo es analizar las principales preocupaciones políticas expuestas en El Iris por Valdés, hombre influyente como editor de periódicos tanto en Jalisco como en la capital de la República mexicana. Entre dichas preocupaciones están los siguientes asuntos: las formas de gobierno y la oposición a los burócratas españoles residentes en México; el temor a un ataque de reconquista apoyado por la Santa Alianza; el rechazo a la línea editorial y los encargados del periódico El Sol de la ciudad de México; la derrota de los liberales en España y, por

5 El Águila Mexicana fue fundado en la ciudad de México por Gómez Navarrete, amigo personal y abogado de Iturbide, dos semanas después de su abdicación en marzo de 1823 (Tella, 1994, 159).

a

\begin{abstract}
(31 de diciembre de 1823). Da, pero escucha. El Iris de Jalisco, núm. 14, p. 53.
La libertad de imprenta se estableció en el Río de la Plata por los decretos del 20 de abril y del 26 de octubre de 1811. El primero era copia textual del promulgado por las Cortes de Cádiz el 10 de noviembre de 1810, y creaba una Junta Suprema de Censura; el del 26 de octubre avanzaba en sus disposiciones al proclamar que todo hombre podía publicar libremente sus ideas sin previa censura, y que las disposiciones contrarias a esta libertad quedaban sin efecto. De este modo, el nuevo decreto eliminaba las restricciones, los castigos y las multas que recaían sobre autores e impresores y creaba una Junta Protectora de la Libertad de Imprenta en reemplazo de la anterior.

El director del gobierno Juan Pueyrredón lo envío como representante del Río de la Plata ante la corte española, pero allí tuvo problemas con Bernardino Rivadavia, que a la sazón se desempeñaba como delegado de las Provincias del Río de la Plata en la misma corte y quien lo acusó de ser autor de un folleto en el que criticaba la revolución rioplatense. Poco después el gobierno de Pueyrredón cayó, por lo que Valdés no volvió a esa región y se dirigió a México: Andrews, 2012, p. 59.
\end{abstract}

Letras Históricas / Número 19 / Otoño 2018-invierno 2019 / México / pp. 157-179 / ISSN: 2448-8372 
último, el retorno a México de Agustín de Iturbide. Se buscará a partir de ahí conocer las características de su ideología y propuestas en un momento coyuntural decisivo para los primeros años del México independiente, cuando se debatía en el Congreso nacional y en los de los estados, en las publicaciones periódicas y en los círculos de opinión del país en general, el futuro ordenamiento del Estado nacional. Considero que revisar esto contribuirá a identificar las contradicciones y los problemas que aquellos hombres enfrentaron y que caracterizaron cuando menos toda la primera mitad del siglo XIX en el país.

Es también un propósito de este estudio revisar la forma en la que los distintos grupos políticos de entonces protagonizaron una disputa en la cual la prensa fue un factor decisivo para la orientación de la opinión pública, ya que manifestó los intereses de los editores así como los de los sectores a los que éstos representaban utilizando un discurso que pretendía, y muchas veces conseguía, ser persuasivo. El propio Valdés apuntó la existencia de al menos cuatro divisiones en la lid política del momento en el país: los monárquico borbonistas, los iturbidistas, los republicano centralistas y los republicanos federalistas. ${ }^{9} \mathrm{Al}$ revisar este panorama desde la óptica del editor cubano se dedican las siguientes páginas, utilizando para ello como fuente y objeto de estudio primordial El Iris de Jalisco, material del que fue autor y responsable único.

\section{El escenario}

Entre diciembre de 1823 y febrero de 1825, meses en los que circuló este medio impreso, México estaba en pleno proceso legislativo para constituirse como nación después de la abdicación de Agustín de Iturbide en marzo de 1823. En ese contexto, tras el fracaso del Imperio, las regiones que conformaron la otrora Nueva España consideraron que la alianza que habían establecido en torno a aquel gobierno se había roto y reclamaron el ejercicio de su soberanía, condicionando su asociación a que ninguna de las partes se atribuyera la supremacía (Olveda, 2003, p. 191).

En este punto vale la pena recordar que hacia $1823 \mathrm{Jalisco}$, en combinación con el Bajío, mostró un alto potencial separatista respecto del resto del país. ${ }^{10}$ Guadalajara tenía su propio Consulado, su Audiencia y

(22 de diciembre de 1823). Hasta otra vez. Federación. El Iris de Jalisco, núm. 10, pp. 37-38.

Fue precisamente por esos intentos separatistas que Jalisco fue castigado en 1824 por el gobierno central con la separación del territorio de Colima, que en 1857 fue elevado al rango de estado libre y soberano. 
había sido capital del Reino de la Nueva Galicia. Su influencia podía extenderse fácilmente a las provincias internas de Zacatecas y San Luis Potosí, desde donde tenía posibilidades de prolongarse hacia el puerto de Tampico (Tella, 1994, pp. 155-156). También el Congreso de Yucatán emitió un voto por la independencia bajo un sistema popular representativo republicano federal, cuya estipulación más importante era la de no injerencia de la federación en lo que concerniera al gobierno y la administración interna de los estados. ${ }^{11}$

De esta manera Jalisco, Zacatecas, Yucatán, Coahuila, Durango, Guanajuato, San Luis Potosí y Tamaulipas mostraron su preferencia por un modelo que otorgara plena autonomía a las provincias, puesto que desde su perspectiva era a éstas a quienes correspondía el ejercicio de la soberanía dentro de sus demarcaciones territoriales; eran también los estados con economías más consistentes (Gantús, Gutiérrez, León, 2008, p. 127).

En opinión de los legisladores tapatíos, las provincias tenían el derecho de cobrar y retener los impuestos correspondientes a sus jurisdicciones, esto sin dejar de reconocer un centro de unión para todas, que sería la federación; es decir, el control de los impuestos y de las rentas públicas fue la base en la que se apoyó su demanda. De hecho, sus propuestas políticas tendían más bien a un modelo de confederación, ya que aspiraban a convertir a las provincias en entidades libres y soberanas, dispuestas a delegar en el gobierno nacional únicamente aspectos como la representación externa y la protección del territorio. Así, una confederación se conforma por entidades libres y soberanas que por intereses comunes sólo delegan una parte mínima de su soberanía al centro de unión, mientras que en una federación las partes que la conforman quedan integradas a un gobierno común. Si bien, hay que considerar que en el discurso político del momento ambos términos se usaron como si fueran equivalentes (Olveda, 2003, pp. 192-200 y Gantús Gutiérrez, León, 2008, p. 137). Pero de cualquier forma, es necesario apuntar que según la opinión de Marcello Carmagnani, el sistema que adoptó México en aquellos años fue el confederal, ya que los estados se reservaron la recolección de los impuestos de los individuos que los conformaban:

Los poderes públicos generales comenzaron relacionándose con colectivos -las entidades estatales-y no con tributarios individuales. Por mucho tiempo no pudo instituirse el principio de individuación tributaria,

11 (17 de mayo de 1824). "Congreso de Yucatán. Dictamen. Augusto Congreso", El Iris de Jalisco, núm. 74, p. 1. 
que acompañaba -y aún caracteriza- a las formas federalistas de gobierno (Arroyo, 2014, p. 141 y pp. 147-148).

En suma, el federalismo (o confederalismo) fue adoptado en México por la presión que ejercieron las provincias. Finalmente, el Acta Constitutiva que establecía la formación de un gobierno denominado federal fue promulgada en enero de 1824, y en octubre de ese año la Constitución ratificó el régimen basado en una soberanía compartida entre la nación y los gobiernos estatales.

Después de comenzar los trabajos del Congreso de Jalisco el 14 de septiembre de 1823, su Constitución fue promulgada en noviembre de 1824; establecía que el estado retenía su libertad y soberanía en todo lo relacionado con su administración y gobierno internos (Olveda, 2003, p. 209). De esta manera, entre las obligaciones de las entidades federativas para ese momento tenemos las siguientes: organizar su gobierno interior sin oponerse a la Constitución y sujetarse a las leyes generales de la unión; proteger los derechos del hombre y del ciudadano; ningún estado podría privar a sus habitantes de la libertad de escribir, imprimir y publicar sus ideas políticas sin necesidad de licencia, pero debería cuidar que se observaran las restricciones y responsabilidad que determinaban las leyes en la materia; tampoco establecería derecho alguno de tonelaje, ni tendría tropas ni navíos de guerra en tiempo de paz; no impondría contribuciones o derechos sobre importaciones o exportaciones, ni entraría en transacción o contrato con otro o con potencia extranjera, ni se empeñaría en guerra. ${ }^{12}$ En otras palabras:

Nuestra constitución política no es más que un pacto de asociación o de federación, en que diversos estados soberanos, libres e independientes unos de otros, se unen y comprometen en ciertos puntos de interés general, cediendo parte de su soberanía y sujetándose a un supremo poder central para que dirija y sostenga a la nación toda, que no es más que la reunión de los estados, evite o componga las diferencias que entre éstos pudieran suscitarse, los defienda de los enemigos exteriores y conserve el orden y tranquilidad en lo interior. ${ }^{13}$

12 (4 de junio de 1824). "Sección segunda. De las obligaciones de los estados", El Iris de Jalisco, núm. 81, p. 2.

13 (24 de septiembre de 1824). "Soberano Congreso. Sesión del día 9 de septiembre", El Iris de Jalisco, núm. 129, p. 3. 
Sin embargo, aquellos que aspiraban a la adopción de un federalismo moderado que no reconociera cuestiones como la soberanía de los estados no cejaron en su propósito de que dicho sistema fuera el elegido. Por ejemplo, en un discurso pronunciado durante el primer Congreso Constituyente el 15 de diciembre de 1823, fray Servando Teresa de Mier, diputado por Nuevo León, sostuvo la necesidad de instaurar una federación en sus inicios "muy compacta," "razonable y moderada," que fuera un término medio entre la "federación laxa de los Estados Unidos" y la "concentración peligrosa de Colombia". Tomando en cuenta esas consideraciones, propuso dejar a las provincias las facultades muy precisas para atender a las necesidades de su interior sin destruir la unidad del país para enfrentar amenazas externas, como la de la Santa Alianza. Este tipo de federación era en opinión de Mier más acorde con la educación de los mexicanos (Teresa de Mier, 1977, pp. 272-308). Es decir, estimaba que sólo una soberanía que residiera en la nación podría preservar la unidad necesaria en esos momentos (Gantús Gutiérrez, León, 2008, p. 133).

Así, durante los meses comprendidos en esta investigación se desarrollaron las discusiones para dar forma a la Constitución que se promulgaría en octubre de 1824. Como veremos, los temas abordados en El Iris están estrechamente vinculados con ese proceso, y a través de sus páginas Valdés buscó incidir en el ánimo y las intenciones políticas de los personajes públicos que estuvieron inmersos en esta tarea.

\section{Los temas políticos que ocuparon}

\section{a Valdés en El Iris de Jalisco}

En cuanto a las formas de gobierno abordadas por Valdés en El Iris, sobresale el federalismo, por el cual expresa su apoyo irrestricto y del cual hizo la apología en el periódico a partir de su admiración por los Estados Unidos como primera república federal exitosa en el ámbito americano, que debía ser un ejemplo para México y para toda Hispanoamérica; como ya han señalado otros autores, también encontramos la ponderación del sistema legislativo inglés (Andrews, 2012, pp. 55-57 y 64-70).

Por otra parte, un tema significativo fue su recelo respecto de los españoles residentes en el país, dirigido en particular hacia los que desempeñaban algún empleo o cargo gubernamental y, derivado de esto último, su temor a un posible intento de reconquista por parte de España apoyada en la Santa Alianza, ${ }^{14}$ motivo por el cual publicó todo tipo de noticias

14

Tratado firmado en septiembre de 1815 por los monarcas de Prusia, Rusia y Austria. Su objetivo era mantener las monarquías absolutas en Europa después de la caída de 
relativas a la inminente organización y posterior desembarco en el país de tropas españolas o al servicio de la antigua metrópoli, que aprovecharían el enclave que conservaban en San Juan de Ulúa para adentrarse en el país. En concreto, especuló sobre la organización de una expedición de reconquista de México al mando del general Apodaca quien se acompañaría de los militares Venegas y Arredondo. ${ }^{15}$ Posteriormente apuntó que la expedición estaría a cargo del general José de la Cruz. ${ }^{16}$

Ahora bien, Valdés explicó que no daba tales noticias con el ánimo de preocupar a los ciudadanos, sino que se apegaba al deber de todo periodista de "publicar imparcialmente los sucesos prósperos o adversos que amagan a una nación y el de prevenir los ánimos de americanos incautos y apáticos, para que estén alerta y siempre en alarma". ${ }^{17}$

Asimismo, se pueden señalar sus constantes ataques a aquellos a quienes denominó "borbonistas" o defensores de los intereses de los borbones en México, entre los que destacaban en su concepto los editores del periódico capitalino $\mathrm{El} \mathrm{Sol,} \mathrm{por} \mathrm{considerar} \mathrm{que} \mathrm{ese} \mathrm{grupo} \mathrm{era} \mathrm{an-}$ tipatriótico y proeuropeo, dado que sostenía la independencia mexicana bajo una monarquía borbónica conforme al Plan de Iguala y al Tratado de Córdoba, ${ }^{18}$ y representaban también lo que consideraba "el despotismo del centro" para el caso nacional. Así, Valdés exponía que las provincias mexicanas que se habían pronunciado por la federación destacaban por la libertad y el orden de que gozaban.

Como en la lid política del momento los editores de El Sol trataron de desacreditar los discursos de Valdés en virtud de ser extranjero, consideración a la que agregaron la relación de amistad que lo unió a Iturbide y las prebendas que recibió por ello, el cubano, sin negar su anterior filiación iturbidista, argumentó que lo único que le debió al otrora emperador fue una sincera amistad, y apuntó lo siguiente:

sostuvimos el trono de Iturbide, pero esto fue por un impulso de gratitud, porque creíamos que aquélla era la opinión nacional, y porque

Napoleón Bonaparte e impedir el surgimiento y la propagación de movimientos revolucionarios y liberales. (7 de mayo de 1824). "Secretaría de Guerra y Marina", El Iris de Jalisco, núm. 69, p. 3. (17 de septiembre de 1824). "Remitido tomado del Águila", El Iris de Jalisco, núm. 126, p. 2.

(20 de septiembre de 1824). "A los editores del NIVEL", El Iris de Jalisco, núm. 127, p. 2. (25 de febrero de 1824). "Hasta otra vez. Stat pulvere coelum", El Iris de Jalisco, núm. 38, p. 1. 
suponíamos que un tal hombre era incapaz de prostituirse a España; pero antes habíamos sido notados por nuestras ideas republicanas, y después las hemos [sustentado] con la voluntad más firme y decidida. ${ }^{19}$

En esta cita vemos que el editor que nos ocupa vindicó su conducta política señalando que no por haber sido iturbidista se le podía acusar de inconsecuente con las ideas republicanas que siempre había manifestado. Esto fue muy importante para él. En lo relativo a su extranjería, señaló que era un americano perseguido por el gobierno español, mientras que en sus palabras "los solares," independientemente de su nacionalidad, carecían de patriotismo. ${ }^{20}$

Por otra parte, en su concepto los federalistas eran americanos y, por lo tanto, necesariamente amigos de la independencia. Para argumentar la adopción del sistema federal en México consideró que, no obstante que no existía forma de gobierno exenta de inconvenientes, la mejor que el mundo había conocido era la de "Norte América", donde prevalecían la libertad, el orden, el concurso y la prosperidad, en suma, "la fuerza en la asociación y la independencia en los asociados". ${ }^{21}$ En consecuencia, los Estados Unidos eran sin duda el ejemplo a seguir no sólo para México, sino para Hispanoamérica en su conjunto, dado que habían enseñado a Europa la ciencia práctica de la libertad civil y política que el mundo antiguo no había sabido ejercer:

Ese hermoso país, asilo de la virtud, del comercio y la libertad, es por todos títulos el pueblo caudillo de los americanos. Es el más fuerte, el único reconocido por las potencias europeas, el único que ha dado pasos decididos al reconocimiento de nuestra independencia (y el que nos puede defender de un posible ataque de la Santa Alianza). ${ }^{22}$

Opinión esta última con la que difirieron distintas personalidades, como fray Servando Teresa de Mier, quien consideraba que, dadas las

19 
diferencias entre Estados Unidos y México, sería un error para el país imitar dicho ejemplo sin tomar en cuenta las singularidades del desarrollo nacional. Este neoleonés apuntaba que las colonias que formaron los Estados Unidos estaban separadas al momento de su independencia, y que se reunieron en una federación para casos muy concretos, mientras que la Nueva España, estando unida, vendría a separarse por un régimen federal sin que las provincias tuvieran experiencia de gobierno previa (Teresa de Mier, 1977, pp. 272-308). ${ }^{23}$

En el contexto de la admiración del cubano por Estados Unidos encontramos, a partir de agosto de 1824, la inserción de una traducción hecha por Lorenzo de Zavala del capítulo 44 de la obra del abate de Pradt sobre la América del Norte: Resumen sobre América. ${ }^{24}$ Allí el autor subrayó, entre otras cosas, el interés natural de los Estados Unidos por salvaguardar la emancipación del resto del continente. Asimismo, con motivo del proceso electoral en México para el nombramiento de los primeros presidente y vicepresidente del país (10 de octubre de 1824), Valdés apuntó lo siguiente al insertar un largo discurso de George Washington anunciando que se retiraba de la política y comentó: "Las virtudes públicas del general Washington serán siempre un ejemplo que enseñe a los hombres públicos la noble abnegación con que deben proceder en el gobierno de pueblos libres". ${ }^{25}$ Más tarde, y con la misma intención de exponerlo como ejemplo para el caso nacional, reprodujo el discurso de Thomas Jefferson al asumir la presidencia de los Estados Unidos.

Vale la pena recordar que Valdés también expresaba gran admiración por el sistema inglés, y lo cita para explicar la forma en que en dicha nación se lleva a cabo el juicio por jurados, que debía ser considerado en su opinión como un baluarte de la libertad civil, dado que con este procedimiento los juicios se celebraban pública y periódicamente, conservando siempre el orden y la claridad en los procedimientos. De esta manera, el acusado tenía la garantía de que sería juzgado por sus iguales, quienes manifestarían un celo cívico en descubrir la verdad. ${ }^{26}$ Estos comentarios llevan a concluir que para el cubano tanto el sistema inglés como el de los Estados Unidos eran modelos admirables y dignos de imitación para los nuevos países, aunque no dejó de considerar que Inglaterra se regía

\footnotetext{
23 "Una federación como la de los Estados Unidos no le convenía a la nación mexicana e imitarla sería la perdición del país". (18 de agosto de 1824). "Remitido tomado del Sol". El Iris de Jalisco, núm. 113, p. 3. (11 de octubre de 1824). "Política Constitucional". El Iris de Jalisco, núm. 136, p. 1. (5 de abril de 1824). "Amor libertatis nobis es innatus juri". El Iris de Jalisco, núm. 55, p. 1.
} 
por una monarquía, a la que si bien calificó como "moderada," estimó que resultaba una reminiscencia del Antiguo Régimen poco adecuada para el desarrollo óptimo de un país libre:

La Inglaterra tiene un monarca que casi no existe más que en la constitución [...] puede asegurarse que si se encuentra rey en un país libre lo es solo en el nombre y más bien se sostiene por consideraciones que por necesidad. El pueblo lo sufre porque no le es gravoso, lo tolera por conservar una sombra de la forma monárquica en transacción de su libertad, pero mil veces más feliz el pueblo que llega a proscribir hasta su nombre. ${ }^{27}$

Ello no obstante, un par de años antes, en un discurso en el Congreso, nuestro editor expresaba que la monarquía moderada era la invención política "más feliz en línea de sociedad," y que su intención siempre había sido "repeler los embates del republicanismo" (citado en Arroyo, 2011, p. 73). Esto en relación con sus esfuerzos de entonces (1822) para que Iturbide fuera coronado emperador. Así pues, en poco tiempo y probablemente debido a su vasta experiencia y a su propia condición de extranjero, Valdés adecuó sus opiniones políticas a las necesidades que se iban presentando en el país, aunque ello lo llevara a sostener posiciones irreconciliables y evidenciara su propia inconsistencia, esto es necesario tenerlo en cuenta al ocuparnos de su pensamiento y opiniones políticas, actitud que por otra parte tuvieron muy presente sus detractores, como fueron los editores de El Sol.

Volviendo al caso nacional y a la publicación que nos ocupa, escribió en ella que el pueblo mexicano había manifestado cuatro opiniones políticas desde la independencia hasta el momento en que estaba, que fueron, a saber,

1.- Monárquico-borbonistas: opinión sostenida sobre todo por los europeos residentes en el país, que apoyaban la creación de una monarquía regida por alguno de los infantes de la Casa de Borbón, como Francisco de Paula.

2.- Iturbidistas: opinión respaldada por americanos (criollos) simpatizantes de Iturbide después de su caída y que se adhirieron a las ideas federalistas por diferentes motivos: oposición a los borbonistas, a los ambiciosos centralistas, por inclinación, convencimiento, conveniencia

$27 \begin{aligned} & \text { (3 de septiembre de 1824). “Continúan las observaciones políticas pendientes en el } \\ & \text { número 117”. El Iris de Jalisco, núm. 120, p. } 2 .\end{aligned}$ 
o docilidad. Éstos podían ser monarquistas, pero no necesariamente lo eran.

3.- Republicano-centralistas: la preferencia por el centralismo provenía de la provincia y de la aristocracia mexicana y sus relaciones con las provincias aledañas, estaba respaldada por la multitud de empleados de la capital del país, y contaba también con parte del ejército.

4.- Republicano-federalistas: en este grupo se encontraba Valdés, quien apunta que estaba formado por la "masa general de los pueblos", por la gran mayoría de los antiguos insurgentes radicados en las provincias, por el ejército en general y por la opinión iturbidista, desvanecida y amalgamada por un generoso patriotismo. ${ }^{28}$

Las ideas republicanas, como forma de gobierno en la que no había monarca, comenzaron a manifestarse en la otrora Nueva España desde la época de las revoluciones en los Estados Unidos de América y Francia, si bien hasta antes de 1813 no como un modelo para adoptar en el país (Ávila, 2002, pp. 316, y 2009, p. 1335). Esto cambió a partir de la abdicación de Iturbide; entonces, "una vez que había caído el emperador y no había casa reinante, no quedaba más opción que la república" (Ávila, 2009, p. 1338).

Para los republicanos era prioritario defender la representación nacional, y suponían que cualquier tipo de monarquía tendería al despotismo (Ávila, 2002, p. 330). En general, la propensión de los republicanos era mirar el ejemplo de la república federada de los Estados Unidos del Norte para imitarla. Ahora bien, en palabras de Valdés, era natural que entre los antiguos partidarios del imperio iturbidista se encontraran los federalistas, quienes defendían sinceramente este último sistema para liberar a la patria de los borbonistas y centralistas, grupos éstos que eran afines en la percepción del cubano. ${ }^{29}$

Cuando en diciembre de 1823 el Congreso Nacional se pronunció por la adopción de una República representativa popular federal, este editor consideró que la citada disposición se había debido, en buena medida, a la labor de los legisladores jaliscienses, ${ }^{30}$ pues en ese estado tuvo su origen "la voz Federación". ${ }^{31}$ También identificó similitudes entre el acta constitutiva de la nación mexicana y la de los Estados Unidos del Norte,

\footnotetext{
28 Ver nota 8 de este trabajo: "Hasta otra vez" (22 de diciembre de 1823), "Federación", El Iris de Jalisco, núm. 10, pp. 37-38.

29 "Hasta otra vez" (1 de diciembre de 1823). "Federación", El Iris de Jalisco, núm. 1, p. 2.

30 (24 de diciembre de 1823) "Federación", El Iris de Jalisco, núm. 11, p. 2.

31 (10 de mayo de 1824). "Rei argumentum dicam", El Iris de Jalisco, núm. 70, p. 1.
} 
esto último en lo relativo a la conformación del senado compuesto de dos senadores por cada estado. ${ }^{32}$

En lo que toca a los españoles residentes en el país que ejercían algún cargo público, sostuvo la posición de la legislatura estatal jalisciense en el sentido de que todo empleado ibérico que así lo quisiera podía renunciar a su cargo a cambio de recibir una parte proporcional de su sueldo (dictamen aprobado en Guadalajara el 24 de diciembre de 1823):

para mí ha sido de indecible satisfacción el haber visto al Congreso y al Gobierno [de Jalisco] conformes con mis ideas en cuanto a la desconfianza que deben inspirar naturalmente los españoles con influjo en el estado, mientras dure la guerra con España. ${ }^{33}$

Esta opinión le enfrentó directamente con los editores de El Sol, quienes consideraban que semejante medida era inapropiada en un sistema republicano, que debía mantener a todos los ciudadanos los derechos que les habían sido reconocidos al momento de la independencia del país. Sin embargo, Valdés y un grupo importante de la clase política nacional pensaban que no era recomendable conservar a los españoles en puestos claves del gobierno ni de las fuerzas armadas, en el supuesto de que eran súbditos de una nación que estaba en guerra con el país. Así por ejemplo, emprendieron una verdadera campaña en contra de que los militares de origen español desempeñaran puestos directivos en el ejército, y exigieron que personajes como Pedro Celestino Negrete abandonara el Supremo Poder Ejecutivo que compartía interinamente con Nicolás Bravo y Guadalupe Victoria. ${ }^{34}$

Esa controversia con los responsables de El Sol fue bastante ríspida; éstos eran conceptuados por Valdés como borbonistas desafectos a la independencia mexicana. Es habitual encontrar en El Iris comunicados y comentarios sarcásticos respecto de aquellos a quienes el editor denominó peyorativamente "los solares." Además, el cubano apuntaba que dicha publicación de la ciudad de México embaucaba a sus lectores con

32 (3 de diciembre de 1823). "Acta Constitutiva", El Iris de Jalisco, núm. 2, p. 5. Josefina Vázquez considera que la gran deuda de la ley fundamental mexicana de $1824 \mathrm{con}$ el modelo estadounidense fue la forma de representación en dos cámaras (Vázquez, 2003, p. 20). general de la federación”, El Iris de Jalisco, núm.. 44, p. 1. 
"imaginadas apariciones del desgraciado Iturbide" y pintaba como héroes de la independencia a "nuestros enemigos naturales":

El editor del Iris es el objeto del rencor y la rabia de los solares, porque como una roca se opone a los embates de la furia española, y como un argos trasluce y pone en claro los planes y aun intentos con que se nos quiere arruinar; pero los solares podrán [...] calumniarme y promoverme persecuciones, mas siempre me tendrán en batalla. ${ }^{35}$

Así, entre las cosas que Valdés reprochó a "los solares" sobresalen sus ataques al "libertador del Anáhuac," es decir Iturbide, quien era en su opinión el único capaz de rivalizar con el infante Francisco de Paula y demás aspirantes borbones al trono mexicano. ${ }^{36}$

Ahora bien, no obstante la animadversión que encontramos en El Iris contra los españoles, Valdés llegó a apuntar lo siguiente:

Antes he dicho y ahora repito que no todos los españoles son nuestros enemigos; bien conocidos son los que identificados con nosotros en sus opiniones han coadyuvado y sostendrán hasta el cabo nuestra independencia, y abominan la conducta perversa de sus paisanos: éstos son dignos de nuestro aprecio y disfrutarán siempre la gratitud de los americanos. ${ }^{37}$

Sin embargo, a pesar de este comentario, tenemos que el editor que nos ocupa fue muy suspicaz en lo relativo a los españoles, incluso en lo que concernía a los liberales o constitucionales, pues respecto de ellos escribió lo siguiente:

Yo jamás me opondré a que el Estado mexicano sea un asilo abierto a los liberales perseguidos por el despotismo de Fernando, pero sí observaré que estos individuos, generalmente hablando, han dado malas cuentas del elevado encargo que España les cometió [...] Yo desaprobé

3

36$$
\text { visto }
$$

entre dos articulistas, uno en la ciudad de México y otro en Guadalajara" (Palacio, 2006: p. 39).

37 (2 de abril de 1824) "Finaliza el comunicado principiado en el número 52", nota al pie 1, El Iris de Jalisco, núm. 54, pp. 2-3. 
la exaltación con que en las Cortes declararon una guerra enconada a toda institución religiosa. ${ }^{38}$

Es decir, el cubano subraya las diferencias entre su ideología y la de aquellos españoles que buscaban refugio en América después de la caída del régimen constitucional en su nación de origen, por lo que se puede corroborar que respecto a los naturales de la otrora Madre Patria su actitud fue de desconfianza incluso con quienes huían de ella por su oposición al absolutismo fernandino.

Pasando ahora a otro tema fundamental en El Iris, tenemos que hacia el mes de abril de 1824 comenzó a circular en el país el rumor de que Iturbide se disponía regresar a México para reinstaurar el imperio, y que para conseguirlo recibiría ayuda de las autoridades de Jalisco. Entre marzo y mayo de 1823, dicha entidad intentó convertirse en el lugar de la resistencia iturbidista y el monarca tuvo allí sus principales sostenedores, entre los que se destacaron Luis Quintanar y varios diputados, así como el editor Antonio Valdés (Tella, 1994, p. 153). Hacia 1824 persistía entre las autoridades de la federación la idea de que Quintanar, quien se desempeñaba entonces como gobernador provisional de Jalisco, promovía el regreso de Iturbide.

A desmentir dicho aserto se dedicaron varios números de El Iris, donde se insertaron los comunicados de Quintanar así como los de distintos congresistas y militares, especialmente de Anastasio Bustamante (capitán general de las armas de esa entidad), deslindándose de cualquier iniciativa en ese sentido. ${ }^{39}$ De igual manera, Valdés sostuvo que los enemigos del estado calumniaban a los jaliscienses aduciendo que allí se aspiraba a la monarquía o a establecer un poder absoluto. ${ }^{40}$ El editor agregó que "los solares" inventaban cartas intercambiadas entre Iturbide y diversas autoridades de la República para "desacreditar la federación a título de iturbidismo". ${ }^{41}$

Como consecuencia de esta situación, a fines de mayo el gobernador se dirigió a los habitantes del estado advirtiéndoles que el gobierno supremo de la federación tenía la intención de invadir y hostilizar la entidad

\footnotetext{
38 (14 de enero de 1824). "Miscelánea", El Iris de Jalisco, núm. 20, pp. 2-3.

39 (3 de mayo de 1824). "El general Bustamante a la nación", El Iris de Jalisco, núm. 67, pp. 3-4.

40 "Hasta otra vez" (5 de mayo de 1824). "Dominum generosa recusat", El Iris de Jalisco núm. 68, p. 1.

41 "Hasta otra vez" (24 de mayo de 1824). "Oye y verás que cosas", El Iris de Jalisco, núm. 76, p. 1.
} 
con "la fábula del regreso de Iturbide y de la supuesta protección que el estado le brindaría". ${ }^{42}$ Por su parte, Anastasio Bustamante envió una misiva al ejército jalisciense recomendando que se mantuvieran en guardia debido a que el gobierno federal tenía tropas en varios puntos fronterizos del estado y que su objetivo era destruir la federación pretextando la necesidad de una dictadura. ${ }^{43}$

También en mayo de 1824, cumpliendo los pronósticos de quienes así lo sugirieron, Iturbide salió rumbo a México desde Inglaterra, país en el que se encontraba después de abandonar su residencia en Livorno, Italia. En un oficio que envió al Congreso Nacional, expuso el argumento de que quería ayudar a la defensa del país de un inminente intento de reconquista que sería dirigido por el rey Fernando VII con ayuda de la Santa Alianza (Tella, 1994, p. 160). En El Iris se publicó este comunicado el 17 de mayo, así como la respuesta de los congresistas que declararon que quien fuera emperador sería considerado como un traidor si se presentaba en algún punto del territorio nacional, al igual que aquellos que lo apoyaran. ${ }^{44}$

Ahora bien, cuando se conocieron las intenciones de Iturbide, algunos militares comenzaron a referirse a una posible intervención en Jalisco para evitar el apoyo que desde esa entidad suponían podría recibir; así por ejemplo Nicolás Bravo y otros generales mandaron arengas a sus respectivas tropas para que se aprestaran a intervenir en tierras jaliscienses si eso fuera necesario para mantener vigente la forma de gobierno republicano federal que había adoptado el país. ${ }^{45}$ Incluso los diputados por Jalisco en el Congreso Nacional presentaron una queja por esto y pidieron que la asamblea se ocupara del asunto a la brevedad posible. ${ }^{46}$

$\mathrm{El}$ hecho es que este incidente generó movimiento de tropas tanto federales como jaliscienses, y es un claro ejemplo de los problemas que se

42

(10

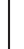

siguiente proclama", El Iris de Jalisco, núm. 81, p. 1, y (7 de junio de 1824) "El general en jefe al ejército de su mando", El Iris de Jalisco, núm. 82, p. 2.

46 (7 de junio de 1824). "Soberano Congreso", El Iris de Jalisco, núm. 82, p. 2-3. 
suscitaron por la disputa entre las facultades de la federación y las de los estados. En este caso, los legisladores locales esgrimieron el argumento de que la entidad podía legítimamente defenderse de las hostilidades del centro, que había puesto tropas en sus fronteras, mientras que Manuel de Mier y Terán, ministro de Guerra, consideró que Jalisco estaba cayendo en insubordinación al excederse en las atribuciones que le señalaba el acta constitutiva, pues no tenía facultades para prepararse militarmente, dado que el movimiento de tropas en el territorio nacional correspondía únicamente al gobierno de la federación para garantizar la seguridad en el interior y exterior del país; y además de esto apuntaron que "el gobierno tiene informes de que ambas autoridades [en referencia a Quintanar y a Bustamante] proceden con el fin de arruinar la república y esclavizar a la nación, sometiéndola al yugo de Iturbide". ${ }^{47}$

En esta coyuntura, Valdés se pronunció a favor de las autoridades del estado de Jalisco, respaldando su derecho a defenderse del gobierno general y subrayando lo que en sus palabras fue la posición moderada del gobierno de la entidad frente a las tropas enviadas por la federación. ${ }^{48}$ Pero hacia mediados de junio de 1824 Nicolás Bravo, que había sido enviado por el Supremo Poder Ejecutivo para "poner orden en la entidad", por disposición del Congreso General aprehendió al gobernador y al capitán general, los separó de sus cargos y los envió presos a Acapulco (Olveda, 2003, 208). ${ }^{49} \mathrm{El}$ poder ejecutivo en el estado fue cubierto por federalistas moderados como José María Castañeda, Rafael Dávila y Juan Nepomuceno Cumplido (Olveda, 2003, pp. 207-208). Posteriormente, el 24 de enero de 1825, Prisciliano Sánchez tomó posesión como gobernador constitucional de Jalisco (Olveda, 2003, p. 212). Meses después, cuando en El Iris se hizo referencia a estas elecciones que dieron el triunfo a Sánchez, el editor apuntó que se debía olvidar "la anterior divergencia de opiniones" en beneficio del estricto cumplimiento de la ley. ${ }^{50}$ Es decir, claramente entre él y las nuevas autoridades del estado se habían presentado desacuerdos.

En ese sentido, cuando se produjo el arresto de las anteriores autoridades y se suscitaron los cambios arriba señalados en la entidad, en la

\footnotetext{
47 (25 de junio de 1824). "Soberano Congreso. Discurso que el exmo. Sr. Ministro de la guerra pronunció en la sesión del día 8 del corriente”, El Iris de Jalisco, núm. 90, p. 1.

48 (25 de junio de 1824). "Comunicado", El Iris de Jalisco, núm. 90, p. 4.

49 A este respecto, Olveda considera que en realidad la aprehensión de Quintanar y de Bustamante obedeció al propósito del Supremo Poder Ejecutivo de calmar las pasiones federalistas en Guadalajara.

50 (3 de enero de 1825). "Elecciones", El Iris de Jalisco, núm. 172, p. 1.
} 
publicación que nos ocupa encontramos la inserción de la traducción del Código Napoleónico, documento que ponía fin a la estructura jurídica del Antiguo Régimen en Francia formulando una serie de normas aplicables a nivel general. ${ }^{51}$ También apareció una declaración del Derecho de Gentes, escrito tomado de El Águila Mexicana, en el que puede leerse, entre otras, la sentencia de que los hombres debían respetar a sus semejantes absteniéndose de someterlos o entrometerse en sus asuntos, ${ }^{52}$ aspectos estos últimos en los que incurrió el Supremo Poder Ejecutivo al atacar a las autoridades de Jalisco.

De todas formas, es relevante que Valdés no hiciera ningún comentario concreto respecto de lo sucedido con el gobernador provisional y el capitán general. Quizá esto se haya debido a la estrecha relación y comunión entre sus ideas y las de Quintanar, particularmente en lo relativo a un federalismo que autorizaba medidas como el movimiento de las tropas de la entidad en lo que se consideró una "legítima defensa" frente a las hostilidades del centro; así, es probable que el editor cubano no quisiera correr la misma suerte que su correligionario y exponerse a ser también apresado o expulsado del estado y luego del país, como ya había sucedido con otros extranjeros metidos en cuestiones políticas nacionales. ${ }^{53}$

Sin embargo, la línea editorial de El Iris no abandonó su propósito de respaldar el sistema republicano federal, como lo demuestra la inserción de un material titulado "Observaciones políticas," firmado por el "Celoso Patriota", donde se hace la defensa de dicha forma de gobierno frente a la monárquica, como hemos visto incluso para el caso de Inglaterra; ${ }^{54} \mathrm{y}$ se sostiene que los garantes de la constitución son los siguientes elementos "pan, armas y escuelas". 55

Ahora bien, en lo relativo al fusilamiento de Iturbide el 19 de julio de 1824 en el municipio de Padilla, Tamaulipas, como consecuencia de su desembarco en Soto la Marina, noticia aparecida en El Iris a fines de julio, ${ }^{56}$ Valdés calificó el hecho como trágico, y publicó semanas des-

51

53

54 mero 132", El Iris de Jalisco, núm. 140, pp. 2-3.

56 (30 de julio de 1824). "Soberano Congreso", El Iris de Jalisco, núm. 105, pp. 2-3.

(14 de julio de 1824). "Código Napoleón. Título preliminar. De la publicación, efectos y aplicación de las leyes en general", El Iris de Jalisco, núm. 98, pp. 3-4.

(21 de julio de 1824). "Derecho de Gentes", El Iris de Jalisco, núm. 101, p. 4.

Como sucedió con el francés Germán Nicolás Prissette, quien fuera editor del Águila Mexicana, expulsado de México en abril de 1824.

(Agosto, septiembre y octubre de 1824). "Observaciones políticas" y "Continúan las observaciones políticas", El Iris de Jalisco.

(20 de octubre de 1824). "Concluyen las observaciones políticas pendientes en el nú- 
pués algunas cartas redactadas en Padilla para confirmarlo, frente al escepticismo de algunas personas que dudaban que el hecho hubiera sucedido. ${ }^{57}$

Con la desaparición física de Iturbide, algunos federalistas consideraron que los centralistas eran los únicos enemigos peligrosos para la nación, quienes además podían unirse a los borbonistas. En su opinión, ambos sectores reunidos tratarían de desacreditar el sistema federal infundiendo desaliento en algunos de los estados para que solicitaran su agregación a otros, con lo que se debilitaría todo el sistema para ir a parar en el centralismo: "Quede pues establecido como punto constitucional irrevocable que en diez años no pueda haber variación ni en la forma de gobierno republicano, representativo federal, ni en la división, número y límites de los estados y territorios". 58

Otro de los temas abordados en la publicación fue el de la dictadura. Según el discurso que encontramos en sus páginas, entre abril y mayo de 1824 se discutió en el Congreso General un proyecto de dictadura para México, o lo que vendría a ser lo mismo, la adopción de un Supremo Director que tendría las facultades de un dictador, iniciativa frente a la que el cubano expresó su franco rechazo, así como el del estado de Jalisco, e incluso citó a otras entidades que también se habían manifestado en contra de ese propósito, como Oaxaca, por contravenir la forma republicana federal de gobierno adoptada en el país. ${ }^{59}$

En su opinión, el único caso en el que se justificaba la instauración de una dictadura era para salvaguardar la independencia. Por ello apoyó desde las páginas del periódico el proyecto de dictadura de Simón Bolívar en el Perú, dado que se trataba de un americano patriota que buscaba preservar la independencia americana. ${ }^{60}$ Para ilustrar esto último insertó la proclama del caraqueño a los peruanos pronunciada el 3 de febrero de 1824, en la que les pidió unión y perseverancia contra las fuerzas españolas. ${ }^{61}$ 71, p. 1. 167).

(20 de agosto de 1824). "Guadalajara", El Iris de Jalisco, núm. 114, pp. 3-4.

(24 de septiembre de 1824). "Soberano Congreso. Sesión del 9 de septiembre", El Iris de Jalisco, núm. 129, p. 3.

"Hasta otra vez" (10 de mayo de 1824), "Rei argumentum dicam", El Iris de Jalisco, núm. 70, p. 1. Y ciertamente por esas fechas algunos iturbidistas sostuvieron que en los círculos gubernamentales se planeaba la instauración de una dictadura (Tella, p. 1994,

(10 de diciembre de 1823). "Advertencia", El Iris de Jalisco, núm. 5, pp. 19-20.

(11 de mayo de 1824). "Guadalajara, mayo 1824" y "Proclama", El Iris de Jalisco, núm. 


\section{Reflexiones finales}

El desempeño del editor cubano Antonio José Valdés en México fue notable. Como hemos visto, entre 1823 y 1826 tuvo una participación pública destacada en el país a través de la publicación de dos periódicos nacionales de relevancia, El Iris de Jalisco y El Águila Mexicana de la capital de la República.

En esos momentos, lo que debatía la clase política en el ámbito nacional era la ordenación del Estado nacional después de la abdicación de Iturbide, y Valdés se sumó a quienes apoyaban la formación de una república federal, obviando que algunos meses antes actuó como uno de los convencidos partidarios de la monarquía moderada de Agustín de Iturbide. Por ello fue precisamente atacado por sus oponentes políticos, en este caso señaladamente los editores de El Sol. En ese sentido, Valdés buscó sobrevivir con éxito al impasse político nacional que implicó el paso de una monarquía constitucional a una república federal, si bien no siempre pudo explicar satisfactoriamente ese cambio de opinión y quedó indefectiblemente marcado por ello. Fue sin duda un político astuto que supo situarse en los momentos adecuados cambiando oportunamente de bando.

En las páginas de El Iris Valdés se refirió a la existencia de cuatro grupos y tendencias políticas en el país: los monárquico borbonistas, los republicano centralistas, los iturbidistas y los federalistas. En su concepto, los dos primeros convergían en opiniones, dado que de no conseguir que el país se constituyera como una monarquía a cargo de alguno de los descendientes de la casa de Borbón que gobernaba en España, la idea era que al menos fuera una república central que favoreciera básicamente los intereses de los sectores asentados desde siempre en el centro del país. De esta manera, borbonistas y centralistas venían a ser equivalentes en su opinión.

A combatirlos ideológicamente dedicó gran parte de su línea editorial, lo que lo convirtió en adversario directo de los sectores de la política nacional que en su criterio respondían a las definiciones señaladas. Su discurso se opuso especialmente a los editores de otro de los periódicos capitalinos importantes, El Sol, y sostuvo con ellos fuertes controversias donde se usaron frases y epítetos ofensivos de ambos lados, lo que llevó a políticos contemporáneos como Carlos María de Bustamante a preguntarse si la ley de libertad de imprenta no debía prever y contener ese lenguaje escrito.

Iturbidistas y federalistas fueron también semejantes en el concepto del editor cubano, ya que los primeros, desencantados del iturbidismo y luego sin la persona del otrora emperador que desapareció con su eje- 
cución en Padilla en julio de 1824, se convirtieron sinceramente al federalismo pues eran "verdaderos patriotas americanos", enemigos de los pérfidos centralistas. En todo caso, tratándose de monarquías o de dictaduras, a veces un mal necesario como en el caso del Perú que tenía en Simón Bolívar a un dictador, era preferible que éstas fueran encabezadas en Hispanoamérica por americanos, que no por borbones o miembros de casas reinantes europeas. Por el contrario, el nuevo continente, guiado por el ejemplo estadounidense, tenía que caracterizarse por su republicanismo.

Ahora bien, debido a su extranjería, Valdés fue atacado por sus adversarios, y en mi opinión esta condición determinó también, al menos en parte, que su federalismo radical, que coincidió en su momento con el de personajes como Luis Quintanar, tuviera que moderarse hacia mediados de 1824, cuando el gobernador interino de Jalisco fue destituido y apresado. El cubano temía ser expulsado del país por sus opiniones políticas y así lo apuntó en la publicación jalisciense. En todo caso, no expresó ninguna opinión cuando Quintanar y Anastasio Bustamante fueron depuestos por disposición del Supremo Poder Ejecutivo de la federación, pero a partir de ese momento encontramos pocas opiniones personales de Valdés vertidas en El Iris, lo que parece indicar una actitud cautelosa y de autocensura. Posteriormente, de acuerdo con lo que él mismo expresó cuando Prisciliano Sánchez asumió el gobierno de Jalisco en enero de 1825, era necesario "olvidar las anteriores divergencias," frase que aclara la difícil posición del editor frente a las nuevas autoridades. No debe entonces resultar extraño que poco después de la investidura de Sánchez la publicación se extinguiera y Valdés saliera del estado.

En suma, hasta antes del descalabro de los federalistas radicales en Jalisco, encabezados por Quintanar y respaldados por Anastasio Bustamante, Valdés emitió juicios en torno a las noticias que le ocupaban y orientó la línea editorial de la publicación en un sentido proclive a los intereses de la entidad, aunque éstos se opusieran al rumbo y las decisiones emanadas del centro de la República, incluso se distinguió por una actitud beligerante en ese sentido, que cambió a favor de una evidente moderación a partir de junio de 1824. Todo esto permite conocer el pulso de los derroteros que fue tomando el federalismo mexicano en estos tempranos años, cuando Jalisco tuvo que alinearse a las disposiciones tomadas por el Supremo Poder Ejecutivo del país.

En cualquier caso, todo indica que desde ese momento ya no fue Jalisco el sitio en el que Valdés se sintió seguro, acogido y respaldado, pues en 1825 cambió su residencia a la ciudad de México para hacerse cargo de la edición de El Águila Mexicana. La circulación de El Iris terminó en 
febrero de ese año, su editor sólo apuntó que nuevas ocupaciones le impedían seguir haciéndose cargo de su elaboración. ${ }^{62}$ Unos meses después apareció como principal responsable del periódico capitalino, seguramente con el objetivo de favorecer el éxito del para entonces ya formalmente constituido grupo de los yorkinos (republicano federalistas) en las elecciones federales de 1826 para diputados y senadores de la República. Cuando eso sucedió dejó también aquella tarea y se le pierde la pista; al parecer murió en México en 1830 (Andrews, 2012, p. 59).

\section{Bibliografía}

Andrews, C. (2012)

El proyecto constitucional de Antonio J. Valdés. Estudios Jaliscienses 87, febrero 2012, pp. 55-71.

Arroyo, I. (2011)

La arquitectura del estado mexicano: formas de gobierno, representación política y ciudadanía, 1821-1857. México: Instituto Mora, Benemérita Universidad Autónoma de Puebla.

Arroyo, I. (2014)

Las formas de gobierno en la historiografía mexicana: federalismo y confederalismo en la obra de Carmagnani. En Y. Celaya (coord.), Diálogos con una trayectoria intelectual: Marcello Carmagnani en el Colegio de México. México: El Colegio de México, Centro de Estudios Históricos, pp: 121-164.

Ávila, A. (2002)

Pensamiento republicano hasta 1823. En J. A. Aguilar y R. Rojas (coord.) El republicanismo en Hispanoamérica. México: Fondo de Cultura Económica, pp. 313-350.

Ávila, A. (2009)

República-México. En J. Fernández Sebastián (dir.), Diccionario Político y Social del mundo Iberoamericano. La era de las revoluciones, 1750-1850. Madrid: Fundación Carolina, Sociedad Estatal de Conmemoraciones Culturales, Centro de Estudios Políticos y Constitucionales, pp. 1332-1345.

Cárdenas Castillo, C. (2010)

Europeos en el México decimonónico: redes, élites y educación. En XIV Encuentro de Latinoamericanistas Españoles, Congreso Internacional 1810-2010: 200 años de Iberoamérica, septiembre, Santiago de Compostela, España.

\footnotetext{
${ }_{62} \mid$ (14 de febrero de 1825). "Despedida", El Iris de Jalisco, núm. 190, p. 4.
} 
El Iris de Jalisco, Guadalajara, Imprenta de Urbano San Román, diciembre de 1823- febrero de 1825. Hemeroteca Nacional Digital de México, consultada entre noviembre de 2015 y marzo de 2016.

Gantús, F., F. Gutiérrez y Ma. del C. León (2008)

La Constitución de 1824. La consolidación de un pacto mínimo. México: El Colegio de México, Centro de Estudios Históricos.

Goldman, N. (2000)

Libertad de imprenta, opinión pública y debate constitucional en el Río de la Plata (1810-1827). Prismas. Revista de Historia Intelectual, núm. 4, 2000, pp. 9-20.

Olveda, J. (2003)

Jalisco: el pronunciamiento federalista de Guadalajara. En J. Vázquez

(coord.), El establecimiento del federalismo en México (1821-1827).

México: El Colegio de México, pp. 189-213.

Palacio, C. del (2006)

Redes de información y circulación de impresos en México. La prensa de Guadalajara en las primeras décadas del siglo XIX. Revista Iberoamericana, núm. 214, enero-marzo 2006, pp. 35-48.

Tella, T. S. di, (1994)

Política nacional y popular en México, 1820-1847. México: Fondo de Cultura Económica.

Teresa de Mier, fray S. (1977)

Profecía sobre la federación mexicana. En Fray Servando Biografía/ Discursos/ Cartas. Monterrey: Gobierno del estado de Nuevo León, pp. 272-308.

Vázquez, J. (2003)

El establecimiento del federalismo en México. En J. Vázquez (coord.), El establecimiento del federalismo en México (1821-1827). México: El Colegio de México, pp. 19-38.

Recibido: 17/03/2017. Aceptado: 13/11/2017

Letras Históricas / Número 19 / Otoño 2018-invierno 2019 / México / pp. 157-179 / ISSN: 2448-8372 